\title{
Fibrossarcoma intranasal invasivo e colienterite secundária em um periquito- australiano (Melopsittacus undulatus) ${ }^{1}$
}

\author{
Raul Antunes Silva Siqueira ${ }^{2}$, William Cardoso Maciel$^{3}$, Windleyanne Gonçalves Amorim \\ Bezerra $^{4}$, Debora Nishi Machado ${ }^{5}$, Ruben Vasconcelos Horn ${ }^{6}$, Ricardo Lucena Barbosa ${ }^{7}$
}

Resumo: Periquitos-australianos (Melopsittacus undulatus) são psitacídeos de pequeno porte, amplamente criados em cativeiro e, por conseguinte, tornam-se passíveis de serem acometidos por inúmeras patologias. Dessa forma, objetivou-se descrever uma ocorrência incomum do fibrossarcoma intranasal associado a enterite secundária bacteriana em um periquito-australiano doméstico. Ao exame clínico, o psitacídeo apresentava deformação lateral do bico associado a uma massa na região da cera, anorexia e apatia, por complicações respiratórias veio a óbito. Na necropsia coletaram-se diversos órgãos para realização do exame histopatológico, adicionalmente foi coletado de suabe clocal e alguns órgãos para isolamento microbiológico e perfil de sensibilidade antimicrobiana. $\mathrm{O}$ achado bacteriano determinou a presença de Escherichia coli resistente a ampicilina e antibióticos do grupo das sulfonamidas. À necropsia, foram observados desidratação e enoftalmia, enterite, abundante tecido adiposo na cavidade celomática e a massa ao corte era endofítica e irregular. Histologicamente, foi averiguada uma proliferação neoplásica no plano nasal do osso ao corte transversal, sendo compatível com a caracterização de um fibrossarcoma. Portanto, ressalta-se a importância de um diagnóstico precoce e diferencial para intervenções terapêuticas imediatas, especialmente, aos da ocorrência incomum como o fibrossarcoma intranasal invasivo, que pode culminar em óbito.

Palavras-chave: Psitacídeos; Tumores mesenquimais; Escherichia coli; Síndrome paraneoplásica.

\section{Invasive intrasanal fibrosarcoma and secondary colienteritis in an budgerigar (Melopsittacus undulatus)}

\begin{abstract}
Budgerigars (Melopsittacus undulatus) are small parrots, widely bred in captivity and, therefore, become susceptible to numerous diseases. Thus, we aimed to describe an unusual occurrence of intranasal fibrosarcoma associated with secondary bacterial enteritis in a domestic budgerigar. At the clinical examination, the psittacine bird presented lateral deformity of the beak associated with a mass in the region of wax's beak, anorexia and apathy and respiratory complications died. At necropsy, various organs were collected for histopathology and, additionally, for collecting swab clocal and some organs for microbiological isolation and antimicrobial susceptibility profile. The bacterial finding determined the presence of ampicillin resistant Escherichia coli and the sulfonamide group antibiotics. At necropsy, dehydration and enophthalmia, enteritis, abundant adipose tissue were observed in the coelomatous cavity, and the cutting mass was endophytic and irregular Histologically, a neoplastic proliferation in the nasal plane of the bone was cross-cut and compatible with the characterization of a fibrosarcoma. Therefore, the importance of an early and differential diagnosis for immediate therapeutic interventions, especially those of the unusual occurrence such as invasive intranasal fibrosarcoma, which can lead to death, is emphasized.

Keywords: Psittacine birds; Mesenchymal tumors; Escherichia coli; Paranoplasic syndrome.

${ }^{1}$ Submetido em 23/10/2017 e aprovado em 06/06/2018

${ }^{2}$ Mestre em Ciências Veterinárias; Doutorando, Universidade Federal de Campina Grande (UFCG), Programa de Pós-Graduação em Medicina Veterinária, Patos - Paraíba, CEP: 58.701-000; E-mail: siqueiraras@ gmail.com

${ }^{3}$ Doutor em Ciências; Professor adjunto, Universidade Estadual do Ceará (UECE), Faculdade de Veterinária, Fortaleza - Ceará, CEP: 60.740-000; E-mail: william.maciel@ymail.com

${ }^{4}$ Doutora em Ciências Veterinárias; Universidade Estadual do Ceará (UECE), Fortaleza - Ceará, CEP: 60.165-120; E-mail: windleyanne@yahoo.com.br

${ }^{5}$ Mestre em Ciências Veterinárias; Universidade Estadual do Ceará (UECE), Fortaleza - Ceará, CEP: 60.165-120; E-mail: deboranishi@ gmail.com ${ }^{6}$ Doutor em Ciências Veterinárias; Professor Adjunto, Universidade Federal Rural de Pernambuco (UFRPE), Garanhuns - Pernambuco, CEP: 55.299-435. E-mail: rubenhorn@hotmail.com

${ }^{7}$ Doutor em Medicina Veterinária; Professor Adjunto, Universidade Federal da Paraíba (UFPB), Areia - Paraíba, CEP: 58.397-000; E-mail: rblucena@gmail.com
\end{abstract}




\section{Introdução}

Os Periquitos australianos (Melopsittacus undulatus) são psitaciformes de pequeno porte, atingindo entre 17-22 centímetros, vivem em média doze anos, e a sexagem macroscópica ocorre através da coloração da cera, saliência encontrada acima do bico, onde nos machos é azulada e nas fêmeas rósea ou bege-claro (Hickman et al., 2001). Possuem dieta baseada em grãos, que armazenam e digerem inicialmente na saculação do esôfago conhecida como papo, e portanto sua microbiota do trato digestivo deve ser em geral composta por bactérias Gram-positivas (Lamb et al., 2014; Orr, 1986; Scanlan; Graham, 1990). As neoplasias chegam a acometer cerca de $3-4 \%$ dos psittaciformes, dentre $12-70 \%$ destas acometem o tegumento e cerca de dois terços a espécie $M$. undulatus. Nesta espécie os de testículos são mais frequentes, seguidos pelos de tegumento, dentre eles os fibromas e fibrossarcomas (Ramsay et al., 1993; Alistair, 2005).

Os fibromas são tumores benignos de fibroblastos, minimamente invasivos, sem potencial metastático, crescimento lento e abundante estroma colagenoso, já os fibrossarcomas são malignos, irregulares, localmente invasivos, recidivantes após ressecção cirúrgica, todavia pouco metastático (Reavil, 2004). A Escherichia coli é uma enterobactéria Gramnegativa anaeróbica de morfologia bacilar, considerada possível patógeno para aves quando pertencente ao grupo Avian Pathogenic E. coli (APEC), podendo ser um agente primário ou oportunista, causando as seguintes apresentações clínicas: colisepticemia, coligranuloma, aerossaculite, sinusite, pericardite, osteomielite, colienterite, dentre outras (Janssen et al., 2001).

O objetivo deste relato é descrever um fibrossarcoma na sua forma intranasal incomum em um periquito-australiano doméstico com enterite secundária causada por E. coli.

\section{Material e Métodos}

Em outubro de 2014, um macho adulto de cinco anos, da espécie $M$. undulatus foi trazido ao Laboratório de Estudos Ornitológicos, situado na
Universidade Estadual do Ceará, para atendimento clínico. Durante a anamnese foram observados baixo peso corporal (23g), apatia e massa na região da cera com deformação lateral do bico. Quando questionado, o tutor relatou ausência de lesões anteriores ou fratura na região e uso de ivermectina tópica local, além de anorexia progressiva e diarreia, entretanto nenhum uso de antibioticoterapia foi realizado. A ave morreu ao término do exame clínico com dispneia intensa e consequente parada cardiorrespiratória. A coleta do suabe cloacal para isolamento microbiológico e o exame necroscópico foram realizados posteriormente. Todos os procedimentos estiveram de acordo com o consentimento do proprietário e aprovação de Comitê de Ética para o Uso de Animais da Universidade Estadual do Ceará (CEUA/UECE) sob o protocolo 1586195/2015.

A necropsia foi realizada próximo ao bico de Bunsen e com material esterelizado, e dessa forma foram coletados de forma asséptica fígado, baço, pulmão, coração, rins, saco aéreo, seio nasal e intestino para isolamento microbiológico. Fragmentos de encéfalo, proventrículo, moela, inglúvio, esôfago, traqueia e músculo esquelético foram acondicionadas em formol a $10 \%$ para processamento histopatológico. Após a fixação, amostras ósseas foram descalcificadas em ácido nítrico a $5 \%$ por 72 horas, e as demais seguiu-se a desidratação em série crescente de álcool, clareamento em Xilóis e inclusão em parafina, realização de cortes de $4 \mu \mathrm{m}$ e posteriores colorações por hematoxilina-eosina (HE), Tricômio de Masson (TM) e Ácido Periódico de Schiff (PAS).

Para o isolamento microbiológico as amostras de suabe cloacal e órgãos foram acondicionadas em $5 \mathrm{ml}$ de água peptonada por $24 \mathrm{~h}$ a $37^{\circ} \mathrm{C}$, seguindose pela alíquotagem e transferência de cada amostra para tubos contendo caldo Infusão CérebroCoração (BHI) e Seletino-Cistina (SC). Após incubação, foram semeados respectivamente em Ágar MacConkey e Verde Brilhante. Por fim, com base nas características morfoculturais, as colônias isoladas e consideradas puras foram submetidas a bacterioscopia, utilizando a coloração de Gram, e às seguintes provas bioquímicas: Ágar Tríplice

Revista Agropecuária Técnica, Areia-PB, v. 39, n. 2, p. 185-190, 2018

DOI: https://doi.org/10.25066/agrotec.v39i2.36881 
Açúcar-Ferro (TSI), Sulfeto-Indol-Motilidade (SIM), Ágar Lisina Ferro (LIA), Citrato, VogesProskauer, Vermelho de Metila, caldo Ureia e Malonato.

As cepas isoladas foram submetidas ainda ao método de disco difusão, para teste de suscetibilidade antimicrobiana, em disco de Ágar Mueller-Hinton contendo os seguintes discos de antibióticos nas suas respectivas concentrações: ampicilina $(10 \mu \mathrm{g}), \quad$ azitromicina $(15 \mu \mathrm{g})$, clortetraciclina $(30 \mu \mathrm{g})$, ceftiofur $(30 \mu \mathrm{g})$, fosfomicina $(200 \mu \mathrm{g})$, gentamicina $(10 \mu \mathrm{g})$, ácido nalidíxico $(30 \mu \mathrm{g})$, norfloxacina $(30 \mu \mathrm{g})$, polimixina B (300U.I.), sulfonamida $(300 \mu \mathrm{g})$, sulfazotrin $(25$ $\mu \mathrm{g})$ e tetraciclina $(30 \mu \mathrm{g})$. Os diâmetros da zona de inibição foram medidos e comparados com os padrões fornecidos pelo CLSI (2014) ou pelas especificações do fabricante.

\section{Resultados e Discursão}

$\mathrm{Na}$ necropsia observaram-se desidratação, enoftalmia e o aspecto da massa ao corte era escura, endofítica, firme, irregular, medindo $(1 \times 1,3 \times 1 \mathrm{~cm})$ diâmetro, aproximadamente. A abundância de tecido adiposo na cavidade celomática, fígado e baço congestos, alças intestinais enegrecidas em diversos segmentos intestinais com fezes emplastradas ao redor da cloaca também foram observados. Microscopicamente, foram observadas congestão difusa acentuada em fígado, pulmão e rins, no corte transversal do plano nasal havia osso com proliferação neoplásica não encapsulada, infiltrativa, constituída de células alongadas com citoplasma levemente eosinofílico por vezes vesiculoso, bordas indistintas e núcleos variando de ovais a fusiformes com sua cromatina agregada e algumas vezes multinucleação. Acompanhando essas células foi observado um estroma eosinofílico denso entretanto escasso e em meio a este havia abundante matriz osteóide eosinofílica destruída. Numerosos agregados bacterianos basofílicos foram observados na superfície da massa e quando realizada coloração de Tricrômio de Masson, o estroma que acompanha e circunda o tumor, apresentou leve marcação azul magenta das fibras colágenas em quantidade ínfima, entremeadas e em sentidos avulsos (Figura 1).
A descrição é compatível com fibrossarcoma pelo intenso pleomorfismo e escassez de tecido conjuntivo e o quadro geral de congestão sistêmica caracteriza um choque circulatório promovido pela enterite bacteriana e pela limitação respiratória mecânica do trato superior devido ao tumor. $\mathrm{O}$ acometimento invasivo no limbo do bico de periquitos-australianos com infiltração intranasal de um fibrossarcoma e coloenterite secundária causando morte, não tem sido descrita na literatura. Estes sarcomas de tecido fibroso em aves são frequentemente relatados no tegumento, seja ao redor da cera ou bico, em asas e membros inferiores, já foram descritos em psitacídeos, na pele da região do carpo e face em araras-canindé (Lamberski; Théon, 2002; Ramsay et al., 1993; Reavil, 2004), entretanto sem descrições de metástases infiltrativas.

A ave veio a óbito antes mesmo de qualquer procedimento interventivo ou diagnóstico, mas a biópsia excisional ou a citologia aspirativa podem ser bem empregadas, onde nesta última para avaliação de malignidade registram-se a anisocitose, pleomorfismo, aumento na relação núcleo:citoplasma, padrão de cromatina grosseira, além da possível presença de macrocariose, multinucleação, evidenciação e anormalidade do nucléolo (Paraschiv et al., 2013). A distribuição e aspectos macroscópicos do fibrossarcoma assemelham-se ao fibroma, este último ocupa o tegumento em região de cabeça, pescoço e membros, entretanto histologicamente os fibromas são constituídos por fibroblastos com núcleo em forma de fuso, sem pleomorfismo marcado, com pacotes de tecido conjuntivo em grande quantidade e em diferentes direções (Yeshwantkumar; Nirmala, 2008).

Os aumentos de volume na face de psitacídeos tem sido descritos e devem ser consideradas como diagnósticos diferencias para o fibrossarcoma, dentre eles o carcinoma de células escamosas (CCE) pois em alguns estágios assemelha-se por seu aspecto macroscópico de massa necrótica e exofítica (Figueiroa et al., 2006). 
Fibrossarcoma intranasal invasivo e colienterite secundária em um periquito-australiano ... Siqueira et al.
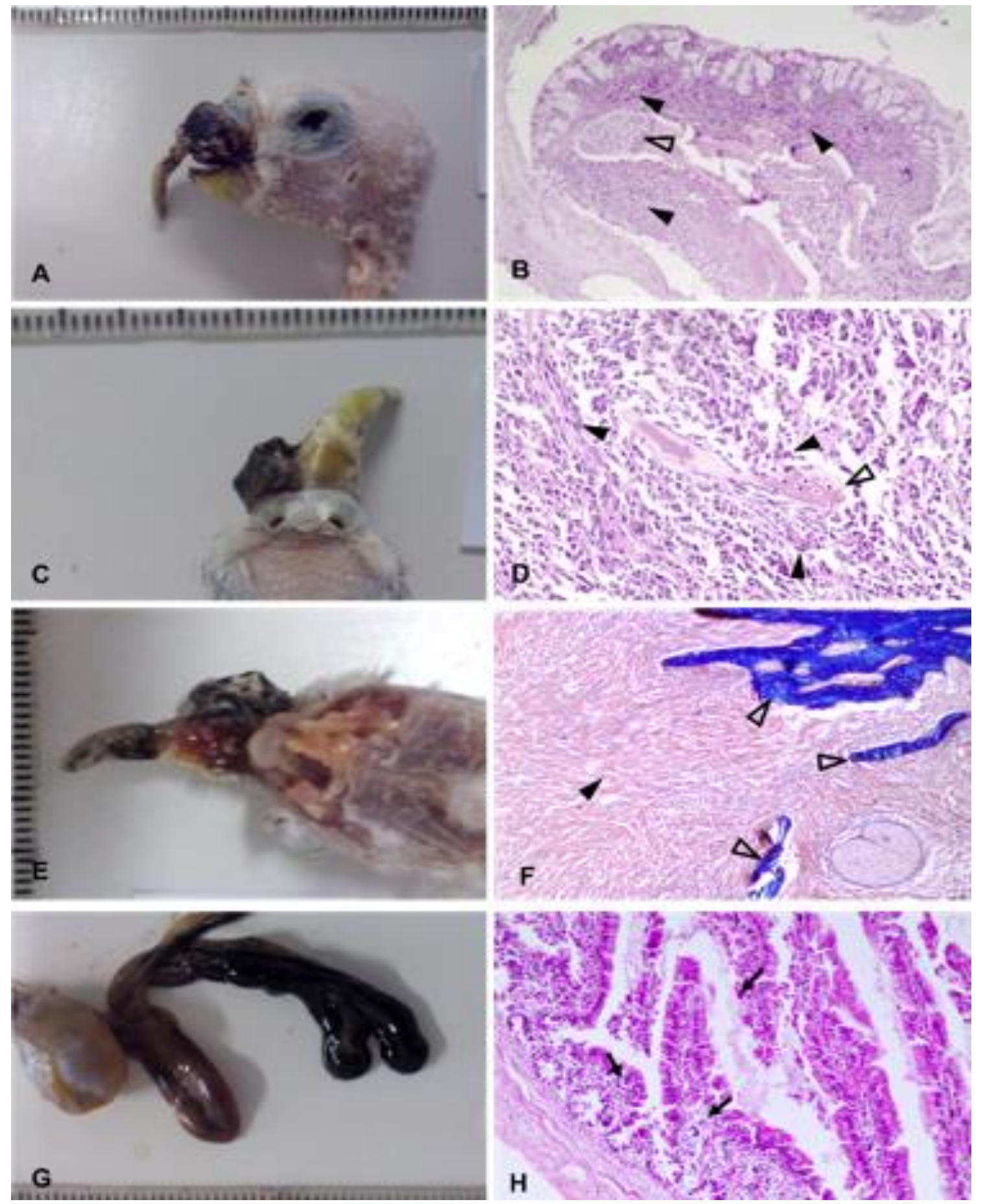

Figura 1 Periquito-australiano (Melopsittacus undulatus), macho, adulto. A, C e E - Macroscopia do fibrossarcoma, em diferenças incidências, definida como massa amorfa, friável, enegrecida e infiltrativa na região da comissura esquerda no limbo do bico. B, D e F - Histopatologia do fibrossarcoma identificada por fibroblastos pleomórficos, em diferentes fusos, com ínfimo colágeno produzido (setas preenchidas) entremeando o tecido ósseo e condróide do corneto nasal (setas vasadas). $\mathrm{G}$ e $\mathrm{H}$ - Macroscopia das alças intestinais enegrecidas e histopatologia da enterite com inflamação mista moderada multifocal da lâmina própria e necrose do epitélio (seta fina).

Revista Agropecuária Técnica, Areia-PB, v. 39, n. 2, p. 185-190, 2018

DOI: https://doi.org/10.25066/agrotec.v39i2.36881 
Fibrossarcoma intranasal invasivo e colienterite secundária em um periquito-australiano ...

Siqueira et al.

Outro tumor descrito na face do M. undulatus, o angiolipoleiomioma pode ser considerado um diferencial e para o diagnóstico utilizam-se colorações de histoquímica de Tricrômio de Masson para evidenciação do abundante colágeno na cor azul, ou quando disponível a imunohistoquímica (Jakab et al., 2013). O tratamento dos fibrossarcomas consiste na remoção cirúrgica com margem de segurança e/ou tratamento quimioterápico. Alguns protocolos utilizam como quimioterápico intratumoral a cisplatina associado a radioterapia (Lamberski; Théon, 2002; Ramsay et al., 1993).

O isolamento bacteriológico do suabe cloacal e do conteúdo fecal obtido da amostra de intestino constatou E. coli (Tabela 1). Os isolados apresentaram sensibilidade a quase todos os antibióticos testados exceto a ampicilina e os do grupo Sulfa (Tabela 2). A E. coli não é uma enterobactéria regular do trato gastrointestinal (TGI) de psitacídeos sadios, logo pacientes psittaciformes oncológicos podem ser passivos de infecções crônicas de caráter viral, bacteriano ou fúngico devido aos danos sistêmicos da síndrome paraneoplásica, a imunodepressão ou possíveis condições higiênicas precárias. Esta situação já foi constatada na traqueíte fúngica secundária ao CCE em papagaio eclectus (Eclectus roratus salomonesis) (Figueiroa et al., 2006; MariettoGonçalves et al., 2010; Lamb et al., 2014). Contudo, no caso do paciente oncológico deste relato, a infecção não foi secundária no local do tumor mas em um outro sistema. $\mathrm{O}$ adenocarcinoma descrito na região da cabeça e cavidade nasal em arara-azul-grande (Anodorhynchus hyacinthinus), similarmente a este relato, predispôs a ave a agentes oportunistas de forma sistêmica e crônica (Noonan et al., 2014).

Tabela 1 Resultado das provas bioquímicas para identificação de Escherichia coli isolada de suabe e conteúdo intestinal de um periquito-australiano com enterite e fibrossarcoma intranasal

\begin{tabular}{cccccccc}
\hline \multicolumn{8}{c}{ Provas Bioquímicas para Escherichia coli } \\
\hline MOT & IND & VM & VP & CIT & URE & LIA & MAL \\
+ & + & + & - & - & - & + & - \\
\hline
\end{tabular}

Tabela 2 Teste de Sensibilidade Antimicrobiana para Escherichia coli isolada de suabe e conteúdo intestinal de um periquito-australiano com enterite e fibrossarcoma intranasal

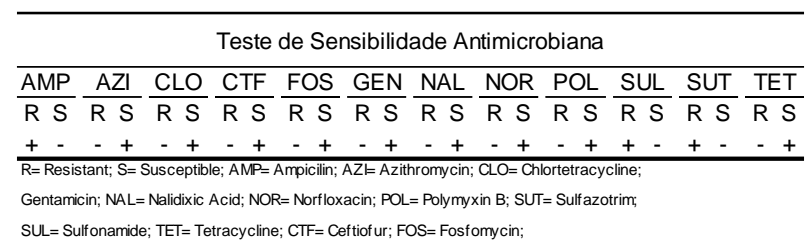

\section{Conclusão}

Portanto, o fibrossarcoma pode acometer de forma invasiva estruturas extra-tegumentares de psitacídeos, comprometendo seu estado clínico geral, tornando-os susceptíveis a infecções intestinais secundárias e possivelmente a morte;

Este tumor deve ser inserido como diagnóstico diferencial dos neoplasmas de pele e tegumento de aves, onde o exame citológico, a biópsia e as colorações histológicas especiais contribuem em seu diagnóstico.

\section{Referências}

Alistair, R. Systemic non-infectious disease. In: Harcourt-Brown, N; Chitty, J. (Ed.). BSAVA Manual of Psittacine Birds. $2^{\mathrm{a}}$ ed. United States: Wiley, 2005. Cap.20, p.262-264.

Ardissino, G.; Possenti, I.; Salardi, S.; Tel, F.; Colombo, E. Co-infection in children with bloody diarrhea caused by Shiga toxin-producing Escherichia coli: data of the North Italian HUS Network. Journal of Pediatric Gastroenterology and Nutrition, v.59, n.2, p.218-220, 2014. https://doi.org/10.1097/MPG.0000000000000420

CLSI - Clinical and Laboratory Standards Institute. Performance standards for antimicrobial susceptibility testing; Twenty-Fourth Informational Supplement. CLSI document M100-S24, Wayne, PA 19087, USA. 2014. 230p. https://www.researchgate.net/file.PostFileLoader.html?id=5 9202a0696b7e4d462166956\&assetKey=AS\%3A496054988 $\underline{533760 \% 401495280134033}$

Fiqueiroa, O. D.; Tully, T. N.; Williams, J.; Evans, D. Squamous cell carcinoma of the infraorbitalsinus rith fungal tracheitis and ingluvitis in an adult Solomon eclectus parrot 
Fibrossarcoma intranasal invasivo e colienterite secundária em um periquito-australiano ...

Siqueira et al.

(Eclectus roratus salomonesis). Journal of Avian Medicine and Sugery, v.20, n.2, p.113-119, 2006. https://doi.org/10.1647/2005-004.1

Hickman, C. P.; Roberts, L. S.; Larson, A. Integrated principles of zoology. $7^{\circ} \mathrm{ed}$. Rio de Janeiro: Guanabara Koogan, 2001. 871p. http://www.usc.es/export9/sites/webinstitucional/gl/investig acion/grupos/malaterra/publicaciones/Invertebrados_Leccio nes/PART_II_Hickmanx_Robertsx_Larson_Integrated_Prin ciples_of_Zoology.pdf

Jakab, C.; Balka, G.; Szabára, Á.; Csaba, C.; Pazár, P. A case of cutaneous angiolipoleiomyoma (angiomyolipoma) in a budgerigar (Melopsittacus undulatus). Avian Pathology, v.42, n.6, p.511515 , 2013. https://doi.org/10.1080/03079457.2013.843158

Janssen, T.; Schwarz, C.; Preikschat, P.; Voss, M.; Philipp, H. C.; Wieler, L. H. Virulence-associated genes in avian pathogenic Escherichia coli (APEC) isolated from internal organs of poultry having died from colibacilosis. International Journal Medical Microbiology, v.291, n.5, p.371-378, 2001. https://doi.org/10.1078/1438-4221$\underline{00143}$

Reavil, D. R. Tumors of pet birds. Veterinary

Clinics of North America: Exotic Animal

Practice, v.7, n.3, p.537-560. 2004.

https://doi.org/10.1016/j.cvex.2004.04.008

Lamb, S.; Sobczynski A.; Starks, D.; Sitinas, N. Bacteria isolated from the skin of congo African grey parrots (Psittacus erithacus), budgerigans (Melopsittacus undulatus), and cockatiels (Nymphicus hollandicus). Journal Avian Medicine and Sugery, v.28, n.4, p.275-279, 2014. https://doi.org/10.1647/1082-6742-28.4.275

Lamberski, N.; Théon, A. P. Concurrent irradiation and intratumoral chemotherapy with cisplatin for treatment of a fibrossarcoma in a blue and gold macaw (Ara ararauna). Journal of Avian
Medicine and Surgery, v.16, n.3, p.234-238, 2002. http://www.jstor.org/stable/30133227

Marietto-Gonçalves, G. A.; Almeida, S. M.; Lima, E. T.; Andreatti Filho, R. L. Detecção de Escherichia coli e Salmonella spp. em microbiota intestinal de Psittaciformes em fase de reabilitação para soltura. Brazilian Journal of Veterinarian Research, v.47, n.3, p.185-189. $2010 . \quad$ http://dx.doi.org/10.11606/issn.16784456.bjvras.2010.26853

Noonam, B. P.; Matos, R.; Butler, B. P.; Southard, T. L.; Morrisey, J .K. Nasal adenocarcinoma and secondary chronic sinusitis in a Hyacinth Macaw (Anodorhynchus hyacinthinus). Journal of A vian Medicine and Sugery, v.28, n.2, p.143-150. 2014. http://www.jstor.org/stable/24623644

Orr, R. T. Biologia dos vertebrados. $5^{\circ}$ ed. São Paulo: Roca, 1986. 512p.

Paraschiv, I.; Tudor, L.; Militaru, M. Relevance of cytopathological diagnosis of fibrossarcomas in budgerigars (Melopsittacus undulates). Scientific Works Series C Veterinary Medicine, v.59, n.3, p. 231, 2013. http://veterinarymedicinejournal.usamv.ro/pdf/2013/vol19 4/art13.pdf

Ramsay, E. C.; Bos, J. H.; McFadden, C. Use of intratumoral cisplatin and orthovoltage radiotherapy in treatment of a fibrossarcoma in a macaw. Journal of the Association Avian Veterinarians, v.7, n.2, p.87-90, 1993. http://www.jstor.org/stable/30135011

Scanlan, C. M.; Graham, D. L. Characterization of a Gram-positive bacterium from the proventriculus of the budgerigars (Mellopsittacus undulatus). Avian Diseases, v.34, n.3, p.779-786, 1990. http://www.jstor.org/stable/1591281

Yeshwantkumar, C.; Nirmala, G. C. Fibroma in a goose. Veterinary World, v.1, n.1, p.24, 2008. http://www.veterinaryworld.org/2008/January/Fibroma.pdf 